ШУЛЕПИН Михаил Владимирович - аспирант Института социологии ФНИСЦ РАН (117218, Россия, г. Москва, ул. Кржижановского, 24/35, корп. 5; mihailshulepin@таil.ru)

ВОРОНОВ Виктор Васильевич - доктор социологических наук, профессор; ведущий научный сотрудник Института социологии ФНИСЦ РАН (117218, Россия, г. Москва, ул. Кржижановского, 24/35, кopn. 5; voronov@isras.ru)

\title{
ОБРАЗОВАТЕЛЬНЫЕ МОДЕЛИ МОДЕРНИЗАЦИИ СОВРЕМЕННОГО ИНСТИТУТА ДОПОЛНИТЕЛЬНОГО ПРОФЕССИОНАЛЬНОГО ОБРАЗОВАНИЯ В ПРАВООХРАНИТЕЛЬНОЙ СФЕРЕ
}

\begin{abstract}
Аннотация. Социологические данные, полученные в ходе нашего и ряда других исследований, позволяют утверждать, что дополнительное профессиональное образование (ДПО) сотрудников органов внутренних дел (ОВД), решая свои основные задачи, тем не менее, характеризуется рядом проблем. Здесь можно отметить чрезмерную централизацию и формализм; то, что оно не вполне отражает актуальные образовательные потребности, а результаты обучения недостаточно влияют на возможности профессиональной мобильности сотрудников ОВД. В работе показано, что модернизация системы ДПО в российских правоохранительных органах нуждается в увеличении степени институциональной открытости и включении в нее элементов неформального образования.
\end{abstract}

Ключевые слова: правоохранительные органы, сотрудники ОВД, дополнительное профессиональное образование, образовательные модели, модернизация

$\mathrm{B}$ работах разных авторов показано, что степень гибкости, открытости и соотношение формального/неформального образования ${ }^{1}$ задают наиболее фундаментальные характеристики самого института дополнительного образования в правоохранительной сфере, от которых во многом зависит решение и других вопросов [Коблов, Хадиков 2016; Лесовик 2010]. Исходя из приоритетности этих двух переменных, можно представить двумерное пространство возможных моделей ДПО в правоохранительной сфере и направлений их модернизации. Поскольку каждая из них образует некоторый континуум, объединение двух континуумов задает двумерное пространство, которое можно представить следующим образом (см. рис. 1). На рисунке цифрами обозначены четыре формы институциональных моделей ДПО, а их модернизация может быть описана как движение внутри координатной плоскости. Дадим краткую характеристику каждого из вариантов образовательных моделей ДПО в правоохранительной сфере.

Модель 1 (закрытое формальное ДПО), хоть и является «идеальным типом», с высокой степенью точности описывает фактически существующую в настоящее время модель ДПО в правоохранительной сфере. В этой модели все дополнительное образование сосредоточено в ведомственных организациях, а все ключевые этапы и элементы образовательного процесса (разработка программ и их содержание, администрирование учебного процесса, само обучение, оценка результатов) находятся под институциональным контролем МВД России. Модель предполагает установку на формальное образование: прохождение по установленным правилам аккредитованных курсов повышения ква-

\footnotetext{
1 Под формальным ДПО имеется в виду прохождение дополнительного обучения на курсах повышения квалификации и программах переподготовки в аккредитованных организациях, а под неформальным - любые другие организованные формы дополнительного образования.
} 
лификации и программ переподготовки с выдачей подтверждающих документов определенного типа, которые и определяют для системы уровень квалификации сотрудников ОВД.

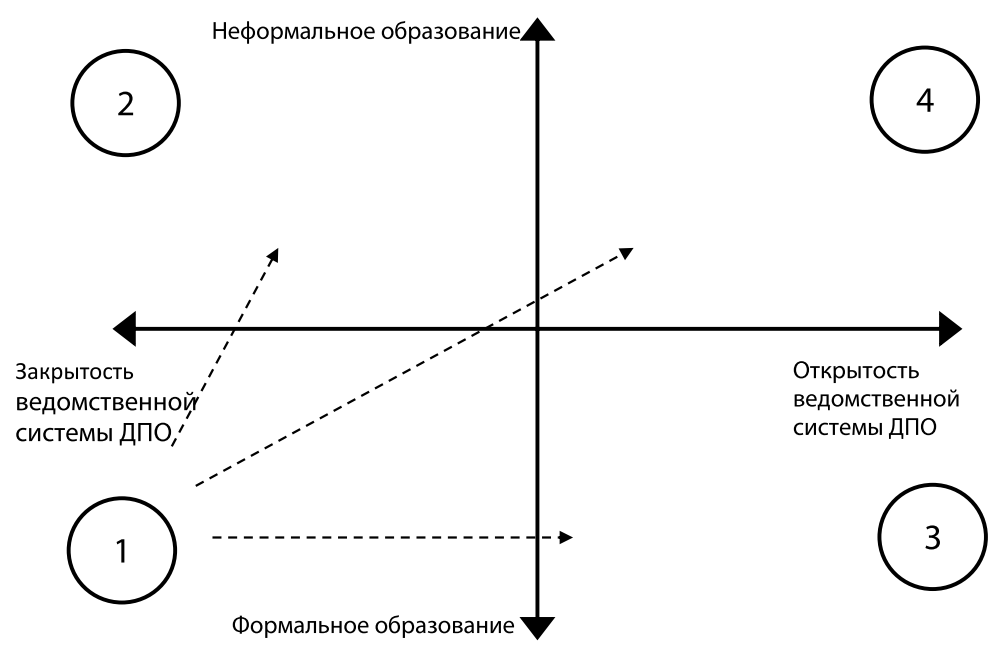

Источник: авторская разработка.

Рисунок 1. Пространство возможных образовательных моделей ДПО в правоохранительной сфере

Модель 2 (закрытое неформальное ДПО) - аналитическая модель организации ДПО, при котором все дополнительное образование осуществляется внутри и силами ведомственных организаций, однако устраняются все формальные требования к периодичности прохождения обучения, формам, видам и продолжительности программ обучения, их содержанию и используемым образовательным технологиям. В рамках такой модели правоохранительная система сохраняет институциональный контроль над дополнительным образованием своих сотрудников, однако принимает радикальные меры по предотвращению формализации и бюрократизации обучения.

Модель 3 (открытое формальное ДПО) предполагает обращение к внешним по отношению к правоохранительной системе источникам компетенций и образовательным ресурсам. Речь может идти об образовательном аутсорсинге, что является нормальной практикой для большинства областей профессиональной деятельности. Модель потенциально может быть реализована, если сотрудники ОВД будут проходить дополнительное обучение в гражданских вузах и институтах, которые имеют подразделения ДПО. Данная модель предполагает ликвидацию ведомственных образовательных учреждений, специализирующихся на ДПО.

Модель 4 (открытое неформальное ДПО) является наиболее отдаленной от существующей в России системы ДПО в правоохранительной сфере. Она также является аутсорсинговой моделью, но, в отличие от предыдущей, не опирается на гражданские аналоги ведомственных программ ДПО, а обращается к большому разнообразию образовательных продуктов, предлагаемых на рынке, - от 
тренингов в бизнес-школах и семинаров до обучения на массовых российских и зарубежных онлайн-курсах (МООК). Такая модель характеризуется наименьшим уровнем институционального контроля и максимальным уровнем свободы самого сотрудника в проектировании образовательной траектории и развитии своих компетенций.

Представленные типы моделей ДПО в правоохранительной сфере могут рассматриваться как основа для разработки направлений модернизации современной российской системы ДПО сотрудников ОВД. Рассмотрим каждую из четырех образовательных моделей модернизации, определив их ключевые преимущества и недостатки, а также возможные направления развития в современных российских условиях.

Модернизация системы ДПО на базе модели 1. Консервативная модель закрытого формального образования, действующая в настоящее время в России, обладает несколькими важными преимуществами, определяющими ее устойчивость. Прежде всего, она является наиболее простой с точки зрения администрирования, обеспечивая высокий уровень институционального контроля над всеми ключевыми элементами дополнительного обучения - от целеполагания и планирования до оценки результатов. Другое преимущество заключается в том, что полный ведомственный контроль позволяет сконцентрироваться на трансфере тех знаний и компетенций, которые в наибольшей степени востребованы в правоохранительной системе и наиболее полно отвечают ее потребностям. В-третьих, существующая система гарантирует вовлечение сотрудников ОВД в повышение квалификации, обеспечивая тем самым рост человеческого капитала даже в отсутствие очевидных стратегических преимуществ, даваемых повышением квалификации, и личностной мотивации части сотрудников. В-четвертых, институциональная закрытость минимизирует выход чувствительной профессиональной информации, знаний и компетенций за пределы системы МВД, предотвращая их неправомерное использование. Однако система закрытого формального ДПО имеет очевидные ограничения, главными из которых являются следующие:

- ограниченность собственного (внутреннего) потенциала для развития профессиональных компетенций по мере усложнения и специализации знаний и компетенций, востребованных в системе правоохранительных органов;

- имеющееся несоответствие между содержанием программ ДПО и образовательными запросами слушателей;

- недостаточная возможность использования мотивационного ресурса самих сотрудников ОВД;

- отсутствие независимой оценки качества и эффективности обучения.

В этой связи можно предложить несколько направлений развития ведомственной системы ДПО, которые не нарушают базовые принципы существующей модели:

1) повышение тематического разнообразия программ ДПО и их актуализация на основе анализа мирового опыта и потребностей правоохранительных органов;

2) расширение возможностей выбора программы ДПО сотрудниками ОВД (введение практики индивидуального консультирования сотрудников по выбору программы, конкурсного отбора заявок на прохождение наиболее востребованных программ и др.);

3) конкретизация условий и принципов влияния ДПО на карьерные возможности и профессиональную мобильность сотрудников ОВД (квалификационные требования для начальствующего состава ОВД носят достаточно общий 
характер и никак не определяют взаимозависимость пройденных программ ДПО и профессионального роста сотрудников) ${ }^{1}$;

4) более активное использование механизма стажировок в качестве способа повышения квалификации;

5) включение элементов горизонтального трансфера знаний в программы ДПО (расширение использования тех образовательных технологий и методов, которые основаны на горизонтальном взаимодействии слушателей. Это могут быть семинары и практикумы, направленные на обмен опытом между слушателями и его рефлексивный анализ, групповые проекты, мозговые штурмы и т.П.);

6) организация системы оценки результатов дополнительного обучения на основе отзывов и экспертных мнений руководства территориальных подразделений МВД (наличие обратной связи со стороны руководства позволит своевременно корректировать содержание программ, используемые методы обучения).

Поскольку предложенные меры направлены на решение проблем института ДПО правоохранительной сферы, не связанных напрямую со степенью его открытости и формальности, они в значительной мере применимы и для других моделей модернизации.

Модернизация системы ДПО на базе модели 2. Данная модель модернизации не требует радикальной трансформации подходов МВД России к кадровой и образовательной политике. Ключевыми преимуществами модернизации на основе модели 2 следует поэтому считать:

- сохранение относительно высокой управляемости и простоты администрирования системой ДПО;

- более высокий уровень гибкости и адаптивности системы ДПО;

- рост личной мотивированности и вовлеченности сотрудников ОВД в повышение квалификации.

Наряду с этими преимуществами у данной модели модернизации есть и относительные недостатки:

- усложнение механизмов включения дополнительного обучения в процесс принятия кадровых решений;

- усложнение процедур выбора и согласования программ, планирования повышения квалификации;

- значительное увеличение нагрузки на образовательные учреждения МВД, вызванное необходимостью расширять перечень программ ДПО;

- повышение требований к преподавательскому составу, их профессиональным, педагогическим и управленческим компетенциям;

- отсутствие доступа к внешним образовательным ресурсам и передовому опыту;

- ограниченные возможности проведения независимого аудита результатов обучения.

Реализация модернизации ДПО по этой модели включают в себя следующее.

1. Существенное расширение перечня видов программ ДПО (разовые или многодневные тренинги для развития коммуникативных и других «мягких» навыков; практические и научно-практические конференции для технологически сложных видов служебной деятельности; конкурсные мероприятия, деловые игры, челленджи, хакатоны и т.п. для формирования управленческих ком-

\footnotetext{
${ }^{1}$ Приказ МВД России от 01.02.2018. № 50 «Об утверждении Порядка организации прохождения службы в органах внутренних дел Российской Федерации» (Зарегистрировано в Минюсте России 22.03.2018 № 50460). Приложение 11. Доступ: https://www.garant.ru/products/ipo/prime/doc/71805114/ (проверено 03.05.2020).
} 
петенций, развития навыков групповой работы и др.). Модернизация системы ДПО на основе модели 2 потребует реформирования ведомственных образовательных организаций.

2. Конкретизация условий и принципов влияния ДПО на карьерные возможности и профессиональную мобильность сотрудников ОВД (включение наличия пройденных программ ДПО в перечень квалификационных требований для замещения должностей начальствующего состава и др.).

3. Изменение процедуры выбора программы ДПО (определить порядок согласования выбранной сотрудником программы ДПО с экспертными комиссиями с последующей оценкой ими результатов обучения).

Повышение качества и практической ценности программ ДПО, как и в случае модели 1 , может быть достигнуто за счет развития механизмов исследования и анализа спроса на профессиональные компетенции со стороны территориальных подразделений ОВД, участия последних в оценке фактических результатов обучения и их соответствия служебной деятельности. Модернизация ДПО на базе модели 2 является, безусловно, более сложной в планировании и реализации. Вместе с тем она предлагает новые средства для повышения качества профессиональной подготовки и снижения рисков сугубо формального подхода при принятии образовательных и кадровых решений.

Модернизация системы ДПО на базе модели 3. Третий вариант модернизации системы ДПО в правоохранительной сфере основан на повышении ее институциональной открытости при сохранении формального образовательного процесса. В этом случае ДПО реализуется не столько в ведомственных образовательных организациях, сколько в других учебных заведениях, как государственных, так и частных, имеющих соответствующую аккредитацию. Ключевые преимущества этой модели заключаются в следующем:

- расширение доступа к внешним источникам профессиональных компетенций;

- рост мотивации из-за внешней конкуренции с ведомственными образовательными организациями, что приведет к росту качества программ ДПО, разрабатываемых в системе МВД;

- сохранение простоты и административной управляемости кадровыми процессами, связанными с оценкой квалификации сотрудников ОВД ${ }^{1}$.

К числу ограничений этой модели следует отнести:

- недостаточную готовность ведомственной системы ДПО к взаимодействию с внешними образовательными организациями;

- несоответствие между принципами централизованного планирования образовательной деятельности в системе МВД и необходимостью взаимодействия с независимыми субъектами;

- снижение возможностей институционального контроля за содержанием программ ДПО и их соответствием потребностям внутренней службы, а также оценкой результатов обучения;

- сохраняющиеся риски формального отношения к участию в программах ДПО со стороны сотрудников, руководства и кадровых структур ОВД.

Анализируя возможности модернизации ДПО в российской правоохранительной системе на основе модели 3 , следует отметить, что участие во внешних образовательных программах возможно только на условиях государственного заказа, и планирование обучения вне учреждений МВД сопряжено со

\footnotetext{
1 Приказ МВД России от 05.05.2018 № 275 «Об утверждении Порядка организации подготовки кадров для замещения должностей в органах внутренних дел РФ» (Зарегистрировано в Минюсте России 27.06.2018 № 51459). Доступ: https://www.garant.ru/products/ipo/prime/doc/71877330/ (проверено 03.05.2020).
} 
сложными процедурами межведомственного согласования, прежде всего с Министерством науки и высшего образования.

Институциональная закрытость современной российской правоохранительной системы, включая ее образовательный компонент, накладывает ограничения на взаимодействие с внешними образовательными организациями. При этом для многих стран с развитой правоохранительной системой (США, Германия) характерна высокая степень открытости, что проявляется в т.ч. в активном использовании внешних образовательных ресурсов и высокой степени самостоятельности самих сотрудников в повышении своей квалификации [Воронов, Шулепин 2019]. Современный российский опыт также показывает примеры успешного выстраивания более открытых отношений изначально закрытыми институтами в сфере образования, например в системе военных учебных центров (ВУЦ) при гражданских вузах [Романова, Карлова 2015]. Существуют все объективные предпосылки для более высокой интеграции ведомственной системы ДПО с гражданским образовательным сектором. Исходя из названных особенностей модели 3 и условий ее реализации в современной правоохранительной системе, могут быть сформулированы следующие направления модернизации ДПО для данной модели.

1. Определение перечня программ ДПО, которые целесообразно сохранить в ведомственных образовательных организациях, с учетом доступности и качества внешних ресурсов (целесообразно сфокусироваться на разработке специализированных программ для формирования уникальных профессиональных компетенций, которые не имеют аналогов в гражданском секторе, таких как следственная деятельность, борьба с терроризмом, и т.п.). Остальные востребованные направления подготовки (правовые дисциплины, психологические знания, современные технологии и пр.) будут осуществляться в рамках образовательной системы РФ. Это представляет дополнительные возможности для специализации и фокусирования ведомственных организаций ДПО на наиболее уникальных программах.

2. Разработка механизмов выбора программ ДПО с учетом направления деятельности, интересов сотрудников и рекомендаций экспертов.

Модернизация системы ДПО на базе модели 4. Модернизация на основе модели открытого неформального ДПО требует наиболее глубокого реформирования сложившейся российской правоохранительной системы дополнительного образования. Эта модель основана на отказе от обоих основополагающих принципов ведомственной образовательной системы: закрытости и автономии, с одной стороны, и опоры на стандартизированные формальные процедуры повышения квалификации сотрудников - с другой. При этом она потенциально обладает преимуществами по сравнению с другими моделями, такими как:

- высокое разнообразие программ, доступных для сотрудников, обеспечивающее гибкость системы ДПО и качество обучения при отсутствии роста нагрузки на ведомственные организации;

- доступ к уникальным компетенциям, формирование которых в системе МВД собственными средствами крайне затруднительно (в высокотехнологичной сфере и за счет потенциальной возможности участия в международном трансфере знаний);

- возможность ведомственных организаций сосредоточиться на разработке уникальных узкоспециализированных программ, востребованных в российских ОВД, и реализации их в современных инновационных форматах;

- рост ценности ДПО для сотрудников ОВД из-за возможности приобрете- 
ния компетенций, которые могут быть востребованными и вне правоохранительных органов.

Относительными недостатками модернизации на основе этой модели следует считать:

- усложнение процедур выбора программ ДПО, оценки результатов обучения, учета освоенных программ при принятии кадровых решений;

- высокая вероятность неприятия изменений со стороны образовательных организаций МВД и кадровых подразделений ОВД;

- необходимость реформирования образовательных организаций МВД, изменения учебных программ, риски сокращения преподавательского состава и др.

Модернизация системы ДПО на основе модели 4 сочетает потенциально высокие возможности и одновременно высокие угрозы для российской системы ОВД. Сотрудники, получающие возможность повышать свой профессиональный уровень за пределами организаций МВД, расширяют спектр доступных для себя профессиональных и жизненных стратегий.

При реализации модели 4 деятельность учреждений ДПО в системе МВД следует трансформировать в сторону усиления их исследовательской, аналитической и экспертной функций, таких как разработка актуальных специализированных программ для конкретных категорий сотрудников ОВД; мониторинг и анализ существующих образовательных возможностей с точки зрения их соответствия потребностям. Это может стать важным стимулом развития самой системы ДПО правоохранительной сферы и превратить ее в передовые центры уникальных компетенций, не имеющие аналогов вне системы МВД.

Выводы. Анализ системы ДПО правоохранительной сферы с точки зрения двух фундаментальных институциональных характеристик - степени открытости и соотношения формального и неформального ДПО - показывает, что для нее характерны высокая степень институциональной закрытости (опора на внутренние образовательные возможности) и формальности (ориентация на формы приобретения компетенций в виде курсов повышения квалификации и программ переподготовки). Модернизация системы ДПО в российских правоохранительных органах может осуществляться как в рамках существующей институциональной модели, так и на основе трех альтернативных моделей, предполагающих увеличение степени институциональной открытости и включения элементов неформального образования. Наличие альтернативных стратегий создает благоприятные условия для профессионального обсуждения и выбора оптимального варианта модернизации системы профессиональной подготовки сотрудников ОВД в соответствии с современными требованиями и тенденциями развития образовательных систем современного общества. Такая модернизация сможет стать эффективным способом решения существующих проблем и реального повышения профессионального уровня сотрудников ОВД.

\section{Список литературы}

Воронов В.В., Шулепин М.В. 2019. О дополнительном профессиональном образовании в зарубежных территориальных системах правоохранительных органов: социологический анализ. - Власть. Т. 27. № 6. С. 291-297.

Коблов Ф.Ч., Хадиков Р.Ш. 2016. К вопросу о совершенствовании профессиональной подготовки сотрудников органов внутренних дел в период прохождения обучения в образовательных организациях МВД России. -Kонцепт: научно-методический электронный журнал. Т. 47. С. 15-19.

Лесовик И.В. 2010. Дополнительное профессиональное образование сотрудников органов внутренних дел как важнейшее условие повышения эффектив- 
ности их профессиональной деятельности. - Вестник Воронежсского института МВД России. № 4. С. 172-175.

Романова Г.А., Карлова Е.Н. 2015. Подготовка кадров для вооруженных сил в гражданских вузах: возможности и ограничения. - Социология образования. № 5. С. 19-29.

SHULEPIN Mikhail Vladimirovich, postgraduate student at the Sociological Institute - branch of the Federal Center of Theoretical and Applied Sociology, Russian Academy of Sciences (bld. 5, 24/35 Krzhizhanovskogo St, Moscow, Russia, 117218; mihailshulepin@mail.ru)

VORONOV Victor Vasil'evich, Dr.Sci. (Soc.), Professor; Leading Researcher of Sociological Institute - branch of the Federal Center of Theoretical and Applied Sociology, Russian Academy of Sciences (bld. 5, 24/35 Krzhizhanovskogo St, Moscow, Russia, 117218; voronov@isras.ru)

\title{
EDUCATIONAL MODELS OF MODERNIZATION OF THE MODERN INSTITUTE OF ADDITIONAL PROFESSIONAL EDUCATION IN THE LAW ENFORCEMENT
}

\begin{abstract}
Sociological data obtained in our and several other studies, suggest that further professional education of employees of internal affairs bodies, solving their main problem, however, has a number of problems. It is characterized by excessive centralization and formalism; does not fully reflect current educational needs and learning outcomes are not enough to affect the opportunities of professional mobility of police officers. The paper shows that the modernization of the APE system in Russian law enforcement agencies needs increasing the degree of institutional openness and including elements of non-formal education in it. According to the results of the study, the authors conclude that the presence of different educational models provides favorable conditions for professional discussion and selection of the optimal option for upgrading the system of professional training of police officers in accordance with modern requirements and trends in the development of educational systems in modern society. Such modernization can become an effective way to solve existing problems and actually improve the professional level of police officers.
\end{abstract}

Keywords: law enforcement agencies, police officers, additional professional education, educational models, modernization 